\title{
AZEVEDO AMARAL E O SÉCULO DO CORPORATIVISMO, DE MICHAEL MANOILESCO, NO BRASIL DE VARGAS
}

\author{
Trata-se de uma dessas obras, cuja leitura, no momento atual, é \\ imprescindível a todos que desejam conhecer o sentido das transformações que \\ se operam na mentalidade política das gerações de hoje. E quando no Brasil \\ temos o dever precípuo de cooperar ativamente na obra da nova organização \\ nacional instituída pela Constituição de 10 de novembro [de 1937], \\ esta tradução apresenta inexcedível interesse atual e constitui um grande \\ serviço prestado à cultura brasileira pela casa editora que a promoveu.
}

Azevedo Amaral, Prefácio de O século do corporativismo, julho de 1938.

A década de 1930, no Brasil, está indissociavelmente ligada a um dos mais importantes eventos da história do país, o qual, inclusive, tomou para sua designação essa marca temporal: a Revolução de 30. Importante não apenas em visão retrospectiva, própria aos historiadores, mas igualmente no julgamento de seus contemporâneos, que diagnosticaram de imediato que se vivia um tempo de "crise" e de mudanças no Brasil e no mundo. Naturalmente, o crack da bolsa de Nova York, em 1929, já havia anunciado a gravidade dessa crise e, no caso do Brasil, também os descontentamentos de diversos segmentos sociais e as revoltas armadas contra o pacto político que sustentava a Primeira República (1889-1930). Tais eventos, que indicavam o fortalecimento das oposições civis e militares ao regime, tinham antecedentes de pelo menos uma década, articulando-se ao descrédito no liberalismo, que conduzia, internacionalmente e cada vez mais, à defesa de "soluções" autoritárias.

Feita a revolução, abre-se um período dominado pelos confrontos intraelites e pela incerteza política, exacerbado pelas dificuldades econômicas em que o país mergulhou pelo colapso do mercado internacional, particularmente severo quando atingia economias exportadoras e dependentes de praticamente um único produto agrícola (o café), como o Brasil. Mas, passados os anos 
iniciais da década - muito conflituosa, pois se chegou até a uma guerra civil -, conseguiu-se a retomada da economia, bem como um acordo quanto à arena legítima para o desenvolvimento de um debate político sobre uma nova arquitetura institucional para o país: uma Assembleia Nacional Constituinte. Tal acordo durou pouco, sendo soterrado por um processo de radicalização política à direita e à esquerda, alimentado pelas críticas aos procedimentos liberais, que chegaram ao desprezo e abandono da Constituição de 1934. Um encaminhamento que apontou para o aprofundamento da crença na falência internacional da teoria liberal, em particular do liberalismo político, expresso por instituições como o Parlamento, e por práticas como a da representação por meio de eleições, partidos e voto. Seguindo a tendência mundial, o Brasil iria suprimir tudo isso em 1937, quando um golpe civil e militar instituiu a ditadura do Estado Novo sob a chefia do presidente Getúlio Vargas.

Assim, se desde os anos 1920, boa parte da intelectualidade brasileira era desafiada a pensar as razões do "atraso" econômico-social do país e os motivos da "inadequação" do liberalismo político à nossa "realidade", produzindo análises relevantes, que assumiam, em geral, o formato de ensaios histórico-sociológicos, os anos 1930 só acentuariam tal interesse e produção. As questões identificadas ainda durante a Primeira República ganhavam, de um lado, uma gravidade inusitada, e de outro, encontravam possibilidades de intervenção humana, nunca antes experimentadas, justamente em função do episódio revolucionário e de seus múltiplos desdobramentos, quer na esfera política, quer na socioeconômica. É justamente em função desse contexto mais amplo - que é nacional e internacional -, que a literatura brasileira que trabalha no campo da história política e da história cultural acentua a indissociabilidade entre as contingências que marcam as décadas de 1920/30 e o crescimento do que se convencionou chamar de "estudos brasileiros", voltados para a produção de diagnósticos e prognósticos sobre a "realidade nacional".

A reflexão aqui proposta abarca esse amplo e diversificado campo de "estudos brasileiros", sendo por isso fundamental entender seu lugar estratégico como instrumento de ação política dos intelectuais do pós-30, assim como suas fronteiras fluidas e abrangentes. Nesse período, em que se está conformando e consagrando o que se estava entendendo por "estudos brasileiros", podemos verificar que eles abraçavam áreas como literatura, história, geografia, etnografia, sociologia, direito, arte, educação, folclore, música e teatro, por exemplo. Tais estudos, como o nome indica, respondiam a questionamentos fundamentais sobre o que era e, principalmente, o que deveria ser o Brasil, buscando fundamentação no conhecimento das "raízes" do processo de formação histórica do país, para uma melhor orientação quanto ao traçado de diretrizes que permitissem ultrapassar nossos "males": ancestrais, coloniais. Só assim, as metas de modernização tão desejadas seriam alcançadas, na medida em que afinadas à "realidade brasileira", e não mais baseadas em utopias 
ou na cópia de fórmulas "estrangeiras", fossem elas quais fossem, sempre inadequadas, irrealizáveis etc. Quer dizer, os "estudos brasileiros" tinham uma profunda interface com os movimentos filosóficos e artísticos que agitaram o entre-guerras em todo o mundo, tendo como objetivo principal a configuração de uma identidade nacional, que orientasse o processo de modernização do Brasil, segundo suas próprias especificidades. Isso, obviamente, exigia que os intelectuais estivessem em contato permanente com os debates internacionais, condição para se poder realizar uma melhor "adaptação" ou "abrasileiramento", como se dizia, de suas contribuições, tendo em vista a resolução urgente dos problemas do país. Uma preocupação que significava tanto um grande interesse pelo mercado mundial de livros, visando sua importação e tradução, como um dinamismo na edição de livros no Brasil: novos autores, novos títulos, mais cuidados de edição etc.

Nesse sentido, o boom dos "estudos brasileiros" que acontece, grosso modo, entre as décadas de 1920 a 1950, é igualmente indissociável de outra revolução que ocorre no Brasil, sobretudo a partir dos anos 1930, no mercado editorial, com impactos e vínculos com o campo educacional e cultural, por um bom tempo. Em texto clássico, "A Revolução de 30 e a cultura" (1989), Antônio Cândido remarcou como as repercussões desse grande evento atingiram os intelectuais e a cultura, apontando como iniciativas que vinham dos anos 1920, no sentido de ampliar a indústria do livro e o número de autores e temáticas nacionais - no bojo dos nacionalismos dessa década -, ganharam vulto no pós-30. Elas eram sustentadas, quer pelo crescimento das editoras, quer pelo engajamento dos intelectuais voltados, de formas variadas, para empreendimentos que pudessem modernizar o Brasil, dessa feita no contexto de um nacionalismo que se nomeava como democrático e autoritário.

A década de 1930 é, assim, profundamente marcada pela expansão da produção e distribuição de livros, se não da mesma forma no grande território nacional, ao menos em certos estados, como São Paulo, Rio de Janeiro e Rio Grande do Sul, que terão editoras importantes e muito ativas. Entre seus empreendimentos, algumas iniciativas se destacam, como a produção de revistas de "alta cultura" e, em especial, a organização de coleções, que se tornaram um lugar decisivo para a circulação de ideias e o reconhecimento de autores, sobretudo daqueles que se identificavam com os "estudos brasileiros". Nesse sentido, para se dimensionar a importância dessas coleções, vale citar a Brasiliana, dirigida pelo educador Fernando de Azevedo, da Companhia Editora Nacional, de São Paulo, que se inicia em 1931; a Documentos Brasileiros, dirigida pelo historiador Otávio Tarquínio de Sousa, da José Olympio Editora, do Rio de Janeiro, que começa em 1936; e a Biblioteca Histórica Brasileira, com a supervisão de Rubens Borba de Moraes, publicada pela Livraria Editora Martins, do Rio de Janeiro, de 1940 (sobre o tema, ver Pontes, 1988). Como se vê por seus títulos, tais coleções, que publicaram centenas de volumes, voltavam-se, com destaque, 
para os "estudos brasileiros", sendo uma espécie de guia sobre o que se devia ler para conhecer o Brasil e seus pensadores.

Os intelectuais - editores, literatos, ensaístas, cientistas, professores, jornalistas etc. -, são personagens centrais desse cenário político-cultural que se adensa no pós-30, e no qual uma das questões-chave em debate é a de um novo modelo político de organização do Estado e da sociedade, em função, como se disse, da acreditada total falência do modelo político representativo liberal. Nesse debate, o tema das corporações e do corporativismo tem grande interesse, até porque, desde 1931, o Brasil já possuía uma legislação sindical pautada em orientação corporativista, prescrevendo o sindicato único para "empregados e empregadores", reconhecido pelo Estado e sem qualquer conotação política ou religiosa. Uma lei que seria alterada por força da Constituição de 1934, mas que seria retomada após o golpe de 1937, por um decreto-lei de 1939, que volta a consagrar a organização corporativa em sindicato único por profissões, definindo essa associação como uma "célula básica" da sociedade (assim como a família) e como um órgão de colaboração do Estado.

É nesse contexto político e intelectual, precisamente em 1938, que O século do corporativismo, de Michael Manoilesco, chega ao Brasil, em português. Para nos aproximarmos das formas de apropriação deste "imprescindível" livro, escolhemos como estratégia trabalhar com o intelectual que se dedicou à sua tradução. Antônio José de Azevedo Amaral (março de 1881 - novembro de 1942) era filho de Angelo Tomaz do Amaral, um construtor de estradas que participou dos modernos empreendimentos do Visconde de Mauá, durante o Segundo Reinado. Azevedo Amaral era oriundo de uma família, se não abastada, certamente possuidora de um razoável capital cultural, sendo médico por formação, embora nunca tenha exercido tal profissão. Como muitos jovens de seu tempo, em especial os interessados no "mundo das letras", envolveu-se com o jornalismo e acabou se tornando um profissional reconhecido e atuante nesse meio editorial/intelectual. Foi como jornalista do Correio da Manhã, um dos mais prestigiosos do país durante quase todo o século XX, que viveu na Inglaterra nos anos 1910, mantendo no jornal uma coluna intitulada "Cartas de Londres". As poucas informações sobre sua trajetória de vida acentuam a importância dessa longa estada no exterior, que teria influído em suas posições futuras sobre a centralidade da industrialização para o desenvolvimento de uma nação, em especial se ela tivesse um passado colonial. Retornou ao Brasil em 1916, devido à eclosão da Primeira Guerra Mundial, tornando-se redator-chefe e, em seguida, diretor do Correio da Manhã. Além de sua ligação com esse jornal, também trabalhou na Gazeta de Notícias e no Jornal do Commercio, tendo sido fundador do Rio Jornal e de O Dia, este último muito importante na imprensa do Rio de Janeiro. Também foi um dos organizadores de dois periódicos de "alta cultura", de bastante influência nos anos 1930/40: as revistas Diretrizes e Novas Diretrizes. 
Para além de sua intensa atividade como publicista, escreveu vários livros nos anos 1930, tendo-os publicado nas mais importantes editoras, o que revela seu reconhecimento intelectual e trânsito político e comercial. Seus temas inseriam-se no campo dos "estudos brasileiros", como se vê claramente pelos títulos dos volumes: O Brasil na crise atual (1934); A aventura política do Brasil (1935); O Estado autoritário e a realidade nacional (1938) e Getúlio Vargas estadista (1941). Este último é uma biografia autorizada (e alguns dizem encomendada) pelo próprio Vargas, que lera seu livro de 1938 e "aprovara" suas ideias. Não sendo Azevedo Amaral um funcionário público, pois muitos intelectuais, desde o século XIX, acumulavam e viviam como servidores do Estado, Vargas teria considerado que tal biografia ficava isenta de um laço que poderia comprometê-la, de forma muito explícita, junto ao grande público, algo que não interessava à propaganda do Estado Novo (ver Gomes, 1982). Por fim, Amaral também se vinculou a uma publicação criada pelo Departamento de Imprensa e Propaganda (DIP), Cultura Política, revista que teve enorme influência na divulgação da proposta de "democracia autoritária" do regime, e da imagem de Vargas e de suas realizações.

Morrendo em 1942, pouco depois da publicação de seus dois livros mais comentados, bem como da tradução de $O$ século do corporativismo, Azevedo Amaral não assistiu ao fim da Segunda Guerra Mundial, tendo sua obra o tom, o ceticismo e as esperanças de quem não conheceu o holocausto, a Guerra Fria etc., como diversos de seus contemporâneos. Por conseguinte, vale ressaltar que nosso interesse não se dirige tanto às ideias de Manoilesco, mas sim à leitura que Amaral fez delas em sua própria produção, certamente tendo sua experiência de tradutor como um elemento decisivo.

\section{AZEVEDO AMARAL E A TRADUÇÃO DE O SÉCULO DO CORPORATIVISMO}

Em 1938 foi publicado no Brasil, pela José Olympio Editora, uma das maiores e mais prestigiosas casas editoras do Brasil (sobre a editora ver, entre outros, Villaça, 2001), cuja sede se encontrava no Rio de Janeiro, o livro O século do corporativismo, de Michael Manoilesco. Sua tradução para o português foi feita por Azevedo Amaral e, como sabemos por seu prefácio, datado de 12 de julho daquele ano, fora um pedido da própria editora. Para tanto, foi usada a edição francesa Le siècle du corporatisme (Paris, 1936). ${ }^{1}$ O pedido, segundo o tradutor, fora aceito com muito prazer, não só porque as ideias de Manoilesco estavam em "harmonia intelectual" com o fundamental de seu pensamento, mas principalmente porque ele acreditava que, dessa forma, estaria contribuindo para o "enriquecimento da cultura" do país, ao facilitar o acesso dos leitores brasileiros a tal livro. 
$\mathrm{Na}$ verdade, é bom começar registrando que esse não era o primeiro livro de Manoilesco traduzido no Brasil. Em 1931, por iniciativa de Roberto Simonsen, intelectual e um dos mais importantes líderes empresariais paulistas - um dos criadores do Centro das Indústrias do Estado de São Paulo -, publicou-se, no Brasil, sua Teoria do protecionismo e da permuta internacional (São Paulo, 1931), traduzido do volume francês Théorie du protectionnisme et de l'échange international (Paris, 1929). Desde então, Manoilesco começa a ser apreciado por suas ideias, especialmente as que defendiam políticas de proteção às indústrias nacionais de um país, pelas quais Simonsen e diversos outros empresários de vários estados do Brasil combatiam há décadas. ${ }^{2}$ Publicado no olho do furacão, considerando o impacto da crise de 1929, esse livro fora também traduzido para o inglês e o italiano, o que evidenciava a circulação internacional do "grande economista romeno", incentivada pelo momento de sua divulgação, quando todo o mundo se voltava para as questões da economia e das trocas comerciais, em função do profundo abalo que se vivia.

Para os objetivos deste texto, importa destacar a atenção que o livro despertou e seu papel pioneiro (reconhecido principalmente nos anos 1950), ao apontar o que seria uma "falha" na clássica teoria das trocas internacionais, que pressupunha uma competição perfeita entre mercados e mercadorias. Nele o autor demonstrava que os países produtores/exportadores de bens agrícolas estariam sempre sujeitos ao que chamou de "trocas desiguais", que só seriam superadas se protegessem seu setor manufatureiro. Sua advertência sobre o diferencial de valor comercial entre produtos agrícolas e industriais feria profundamente a premissa de perfeita competitividade dos mercados, evidenciando que os países "menos desenvolvidos/ricos" estariam sempre em desvantagem, caso não recorressem a políticas de proteção, identificadas, por ele, como a melhor forma de enfrentar as "imperfeições do mercado". ${ }^{3}$ Não é difícil imaginar como tais considerações foram recebidas em um país como o Brasil, saído de uma "revolução", sobretudo em momento em que seu principal e mesmo único produto de exportação, o café, praticamente não tinha valor, sendo queimado para alguma sustentação de preços. Para o empresariado, reunido em associações de classe desde a Primeira República, e que acabava de saber que teria que se enquadrar na nova legislação sindical corporativista, devia ser música da melhor qualidade. Uma circunstância que tornou Manoilesco um autor aplaudido em importante faixa do público consumidor de livros.

Portanto, é razoável supor, embora não se tenha encontrado indícios disso, que um intelectual como Azevedo Amaral já conhecesse Manoilesco e soubesse de sua importância para o pensamento político e econômico do país. Traduzir um segundo livro desse autor, em que ele agregava a suas reflexões sobre as trocas desiguais, propostas para um novo tipo de organização social, baseada no corporativismo, era muito atraente. Razão suficiente para que se entenda porque Azevedo Amaral esclarece, em seu curto e muito preciso pre- 
fácio, que sua intenção não era se alongar, não era realizar "um ensaio crítico", como algumas vezes ocorria na escrita desse tipo de texto de apresentação. Seu único objetivo, na medida em que "atribui-se frequentemente aos tradutores solidariedade de opinião com as idéias expostas nos livros de cuja versão se incumbem", era destacar alguns pontos de vista pessoais.

Isso porque ocorria que em algumas questões, muitas vezes de importância capital no livro, o tradutor não acompanhava completamente as ideias do autor, cumprindo deixar bem claro quais eram, a despeito de considerá-lo "uma das expressões máximas das tendências políticas, sociais e econômicas da época contemporânea." Nesse sentido, vale observar que, como seu prefácio é datado de julho de 1938, e como ele diz que a tradução foi uma encomenda da editora, seu trabalho, muito certamente, deve ter se realizado com alguma antecedência, provavelmente desde o ano de 1937. Isso significa que seu andamento já devia estar adiantado ou terminado, quando ocorreu o golpe do Estado Novo, em 10 de novembro de 1937. Dessa forma, é possível imaginar que, no essencial, a tradução tenha sido feita antes da instalação desse regime autoritário, embora o prefácio fosse escrito já em sua vigência. Também é interessante notar que o mais reconhecido e aplaudido dos livros de Amaral, O Estado autoritário e a realidade nacional, no qual ele trata da questão do corporativismo, é desse mesmo ano de 1938, e publicado pela mesma editora, a José Olympio (Amaral, 1938). ${ }^{4}$

Contudo, como um dos grandes objetivos de $\mathrm{O}$ Estado autoritário foi saudar o novo regime e sua Constituição, buscando explicitamente formular diretrizes práticas para seu funcionamento, podemos especular que, ao menos em parte, tenha sido escrito após o golpe de 1937, isto é, logo depois ou concomitantemente à tradução de O século do corporativismo. Ou seja, o que nos interessa assinalar aqui é a proximidade temporal da elaboração dos dois textos, o que pode nos ajudar a entender melhor o pensamento de Azevedo Amaral no que se refere à questão do corporativismo, tal qual ela aparece em seu próprio livro, cuja apresentação tem a data de 20 de janeiro de 1938, portanto um texto escrito antes do prefácio do volume de Manoilesco, que é de julho do mesmo ano.

Azevedo Amaral, nesse momento preciso, era um autor respeitado, caso contrário não estaria numa casa editora como a José Olympio. ${ }^{5}$ Publicado no início de 1938, bem no alvorecer do Estado Novo, O Estado autoritário é considerado por alguns comentaristas do autor uma mera peça laudatória. Mas a maioria dos que estudam seu pensamento insistem que sua adesão ao regime tinha sólidos fundamentos teóricos, sendo seu envolvimento com as propostas autoritárias e corporativistas bastante consistente (ver Lamounier, 1981), ${ }^{6}$ a despeito de, diferentemente de outros ideólogos do regime, como Oliveira Vianna e Francisco Campos, ele não fazer parte da máquina administrativa do Estado do pós-30. De toda a forma, sua adesão se explicita ao aceitar a incumbência 
de escrever uma biografia de Vargas, o que se realizaria com Getúlio Vargas - um estadista, em 1941, um ano antes de seu falecimento.

Pode-se dizer, parodiando o nome de um dos periódicos criados por Amaral, que em O Estado autoritário ele desejava traçar "novas diretrizes" para o regime que se inaugurava. Por isso, no dizer de Bolívar Lamounier, o prefaciador da segunda edição de 1981, o livro é uma autêntica "jurisprudência antecipada", na medida em que a Carta de 1937 é taxada de "quase irretocável", havendo apenas senões na definição da política imigratória (que devia favorecer mais os imigrantes brancos), e no tratamento dado ao capital estrangeiro (que ganhava pouco espaço). Nele, como pano de fundo, Amaral irá se bater por duas teses centrais, que se articulam: a do soterramento dos procedimentos do liberalismo político no Brasil e no mundo; e a defesa do Estado autoritário, como uma terceira via, que se impunha e superava quer o liberalismo, quer o totalitarismo, tanto na vertente fascista, como na comunista.

Como era de seu feitio frisar seus princípios teóricos, defender suas orientações políticas e demarcar os pontos em que seu pensamento não comungava inteiramente com o das propostas que examinava, é bom retornarmos a seu prefácio ao livro de Manoilesco, pois é exatamente esse o móvel das poucas páginas que o introduzem: esclarecer quais são as formulações em que o tradutor não segue o autor, sobretudo porque tal distinção envolve sua principal tese: a afirmação da positividade do que chama de Estado autoritário, que não pode nem deve ser confundido com as experiências chamadas de fascistas (e que Manoilesco, posteriormente, iria apoiar abertamente).

\section{AZEVEDO AMARAL LÊ MANOILESCO: ECONOMIA, POLÍTICA E ESTADO NACIONAL}

O século do corporativismo chegava às mãos dos brasileiros por meio da tradução de um intelectual conhecido e do selo de uma grande editora, o que lhe garantia publicidade e meios para uma boa circulação, dentro dos padrões da época. Azevedo Amaral o apresenta como uma "exposição de grandes verdades", ao demonstrar magistralmente a "revolução profunda" que se operava no século XX no "conceito de Estado e na organização das nações". Era, portanto, um livro de "teoria política" que realizava, com base em uma análise da conjuntura internacional, um diagnóstico sobre questões que afligiam o mundo contemporâneo, com destaque para as de natureza econômica, particularmente aquelas que envolviam os processos de produção e trocas internacionais de mercadorias. Mas o livro não se limitava à demonstração das razões que explicavam as grandes "mudanças" que ocorriam em todo o mundo, e que tinham a Primeira Guerra Mundial como um ponto de inflexão, como que dividindo a história em um antes - o século XIX -, e um depois, quando começa o século 
XX. Seu autor, para Amaral, nele oferecia um verdadeiro "plano de reorganização" das nações ante esse novo quadro mundial, que evidenciava o fracasso das "formulas políticas liberais" até então experimentadas, e dava sentido a seu título: o século XX seria o século do corporativismo, pois as corporações deveriam ser, nesse novo tempo, uma das fontes principais do poder do Estado; o órgão "originário da soberania" do povo; enfim, o elemento central de uma concepção e proposta de nova democracia.

O coração do livro, portanto, para seu tradutor, estava na cabal demonstração do fim de uma era, de um modelo de Estado - o "Estado político" -, bem como de um sistema de produção e trocas - o "livre mercado" -, que imperara durante o século anterior, tendo a Inglaterra como sua maior beneficiária. Ele era um réquiem para o liberalismo, não porque este não tivera valor ou serventia no passado, mas simplesmente porque o mundo se transformara e era preciso que as nações e os Estados se adequassem ao momento de "evolução" que se vivia. A lógica, bem expressa no vocabulário de Amaral (mais do que no de Manoilesco), seguia um paradigma cientificista, orientado pelo evolucionismo, que postulava um movimento de mudanças contínuas e algumas vezes rápidas e violentas (as crises, as revoluções) na história das nações, que precisavam se adaptar às novas etapas que viviam. Cada nação faria isso tanto melhor quanto compreendesse, quer o curso dessas mudanças, internacionalmente (havia fatores externos), quer as condições específicas em que se encontrava para realizar sua "adaptação" (havia fatores internos). Isto é, era preciso conhecer a "realidade nacional" que seria "reorganizada" face às transformações mundiais (políticas, sociais e econômicas), trazidas pelo século XX, articulando-se constrangimentos externos e internos, para maximizar as oportunidades existentes, em especial nos países que estivessem em situação de "atraso".

No caso do Brasil que, para Amaral, acabara de viver sua primeira e autêntica "revolução", o momento era propício e estratégico para uma "reorganização estrutural" da sociedade e do Estado, o que se faria pela adoção das diretrizes corporativistas preconizadas por Manoilesco e outros autores, algumas já em experimentação no país. Por conseguinte, como esclarece, encontrara, no livro, muitas ideias magistrais, com as quais concordava e que até já conhecia, pois, como os leitores poderiam verificar, algumas delas vinham sendo defendidas por ele em vários de seus textos, anos antes da publicação de $O$ século do corporativismo. Quer dizer, Azevedo Amaral, com tais observações, reconhece a imensa contribuição de Manoilesco, mas adverte que suas postulações, com destaque a proposta corporativa, eram compartilhadas por diversos autores, alguns inclusive brasileiros, já circulando pelo mundo há algum tempo. Por isso mesmo, escrevia o prefácio não tanto para enfatizar sua convergência com as ideias do autor, mas principalmente para demarcar sua discordância em relação a alguns pontos fundamentais de seu pensamento, como assinalado. 
Assumindo então um tom compreensivo, explica ao leitor que, como o livro apresentava não apenas novas formas organizacionais, como também novos valores, era natural que o autor não escapasse "dos excessos de confiança" depositados em seus planos. Fora exatamente isso que ocorrera, segundo ele, quando Manoilesco tratava das relações entre fascismo e corporativismo. As simpatias do autor pelo regime italiano certamente fizeram com que não percebesse "a grosseira perversão" do modelo corporativista ocorrida na montagem das corporações fascistas. No exemplo italiano, o que se via, na verdade, era uma inversão da proposta corporativista, pois em vez de as corporações serem as células de organização da sociedade e a origem do poder do Estado, tinham se transformado em "instrumentos mais ou menos burocráticos de um Estado absorvente e onipotente". Ou seja, desdobrando-se esse comentário e examinando-o em paralelo com o livro de Azevedo Amaral de 1938, vemos que ele está insistindo na distinção entre o que considera um Estado totalitário (absorvente e onipotente, como o italiano) e o que vai defender como característica do Estado Novo brasileiro, presente na Constituição de 1937: ser um Estado autoritário, estruturado segundo o modelo corporativista. Nesse caso, as modernas corporações - materializadas nos sindicatos de "empregados e empregadores", nos conselhos técnicos e outros órgãos de "colaboração com o Estado" -, precisavam ter margens de atuação, caso contrário, não cumpririam suas funções de representação dos interesses da sociedade a que se destinavam, não executando a mediação entre Estado e sociedade.

Esta observação não deve ser menosprezada, nem entendida como um simples expediente para se afastar do rótulo de fascista, como durante bastante tempo se afirmou, nos trabalhos sobre Azevedo Amaral. Isto porque, até praticamente os anos 1980, no Brasil, houve um intenso debate sobre o caráter do Estado Novo - se fascista ou autoritário -, havendo todo um conjunto de autores que considerava que essa segunda denominação era um mero disfarce dos ideólogos do regime, que se estendia àqueles que defendiam tal designação, na historiografia e nas ciências sociais, em geral. Entretanto, com o aprofundamento das pesquisas históricas sobre o período e a multiplicação de estudos, em vários países, sobre a natureza dos regimes ditatoriais que se implantaram nos anos 1930 e 1940, tornou-se cada vez mais patente que a distinção entre totalitarismo e autoritarismo não era uma manobra ideológica de intelectuais e políticos, havendo distinções importantes que deviam ser reconhecidas e demarcadas, até porque houve esforços entre os autores daquele período para o traçado do que era um Estado autoritário, assim como no que ele diferia dos "totalitarismos" então existentes. Nesse sentido, Azevedo Amaral é exemplar.

No caso brasileiro, tanto o prefácio de $O$ século do corporativismo como a apresentação de $O$ Estado autoritário e a realidade nacional foram escritos no primeiro semestre de 1938, quando o Estado Novo apenas anunciava suas intenções modernizadoras e moralizadoras. Talvez por isso, "as evidentes e pro- 
fundas simpatias" nutridas por Manoilesco ante o fascismo, que segundo Amaral, prejudicavam seu bom senso, a ponto de tornar o livro, em certos momentos, "ilógico e incoerente", podem ser estendidas a seu próprio trabalho. Assim, também suas simpatias por Vargas e pelo que se anunciava em 1937, igualmente podem ter afetado sua capacidade de análise, o que permitiu que, sobretudo a partir dos anos 1950, seu livro fosse qualificado de apologia simplista, caindo no esquecimento, como ocorreu com outros livros e autores ligados às propostas estado-novistas. De toda forma, visto a posteriori, pode-se dizer que no primeiro semestre de 1938 ainda não se sabia muito bem, por exemplo, como o modelo sindical corporativista brasileiro, implantado desde 1931, mas colocado em funcionamento efetivo pelo Estado Novo em 1939, repercutiria quando em articulação com diversas iniciativas governamentais; nem que órgãos, como o Conselho Nacional de Economia, previsto na Constituição de 1937 e muito elogiado por Amaral, jamais seria implantado.

Tais ponderações, evidentemente, não visam minimizar a adesão de Amaral ao Estado Novo, muito pelo contrário. Elas apenas querem situar o exato momento em que ele louva um regime, que acreditava e desejava fosse autoritário e não totalitário. Esta distinção, que foi construída formalmente em $\mathrm{O}$ Estado autoritário e a realidade nacional, em claro diálogo com o livro de Manoilesco, precisa ser considerada como fundamental para se entender o núcleo de seu pensamento, que rejeitava o liberalismo político e o totalitarismo, entendendo-os como projetos de Estado que não deixavam margens de liberdade para os interesses socioeconômicos se manifestarem. Dessa forma, sua leitura de Manoilesco, como todas as leituras, realizava um processo de seleção, cuja diretriz básica fixava as orientações que deviam ser seguidas pelo Estado em sua missão de organizar corporativamente a sociedade brasileira. Tal projeto exigia o abandono do modelo político liberal, mas sem sufocar ou oprimir os arranjos sociais, como nos totalitarismos, o que não eliminava, de forma alguma, o uso da força e da autoridade para que os fins nacionais ou "o bem comum" fossem alcançados.

Essa é, na teoria e na prática, uma fronteira fluida e difícil de traçar; mais ainda, de implementar. Tudo indica que Azevedo Amaral tinha alguma consciência dessas dificuldades, que extrapolavam quaisquer disputas político-ideológicas mais óbvias. Justamente por isso, ele argumentava que Manoilesco, mesmo com toda a sua simpatia por Mussolini, não conseguira agradar completamente alguns "expoentes ortodoxos" do pensamento fascista. Queria, com tal exemplo, mostrar como era ingrata a tarefa de traçar uma nova arquitetura de Estado corporativo, ainda mais rejeitando o modelo fascista. Mesmo assim, considerava $O$ século do corporativismo um livro "indispensável" para se entender as transformações "da mentalidade política contemporânea". Um livro que precisava ser lido no Brasil. 


\section{O SÉCULO DO CORPORATIVISMO E A TEORIA DAS TROCAS INTERNACIONAIS}

É trivial assinalar, considerando-se o acúmulo de estudos sobre Azevedo Amaral, mesmo que o consideremos ainda pouco numeroso, que ele se destaca entre os ensaístas do período do "redescobrimento" do Brasil por uma reflexão cuja marca específica é a força de uma análise próxima à economia política. Dito de outra forma, apesar de O Estado autoritário não deixar de realizar uma longa e original análise histórico-sociológica da formação do Brasil - como ocorria com praticamente todos os ensaios que lhe são contemporâneos -, esse livro e autor, muito mais do que quaisquer outros, se distinguem pelo peso que dão aos fatores econômicos, internacionais e nacionais, nas explicações construídas para se entender as razões do "atraso" do Brasil, bem como as possibilidades de vencê-las. Nesse sentido, é possível afirmar que o fato de Amaral ter vivido, em sua juventude, na Inglaterra, ao que se alia sua escrita de publicista e suas leituras sobre o corporativismo, com ênfase para Manoilesco, fizeram alguma diferença no panorama intelectual de seu tempo.

O que desejamos fazer, a seguir, é acompanhar, através do exame de alguns pontos de $O$ século do corporativismo e de $O$ Estado autoritário, como as ideias de Manoilesco foram apropriadas por Azevedo Amaral, desembocando em sua tese/proposta fundamental, que pode ser resumida, embora de forma muito esquemática, na defesa de um projeto industrialista que só poderia ser de fato implantado por um Estado autoritário, organizado segundo o modelo corporativista. Dessa forma, se as sociedades "evoluíam" continuamente, a grande mudança que deveria ser promovida no Brasil era de natureza econômica, significando uma transformação profunda em um país que, por séculos, fora agroexportador, e que precisava se tornar urbano-industrial para se enriquecer e modernizar, enriquecendo assim seu povo e se impondo no mercado internacional.

Evidentemente, como se assinalou, propostas industrialistas não eram uma novidade do Brasil dos anos 1930, havendo, durante toda a Primeira República, defensores de políticas protecionistas (geralmente usando tarifas alfandegárias), que favorecessem a produção da indústria nacional. ${ }^{7}$ O que era novo, por conseguinte, no projeto de Azevedo Amaral, era o contexto internacional de crise em que eram apresentadas, bem como sua explícita articulação com um modelo de organização sociopolítica, baseado nas corporações, que ganhava espaço mundialmente ante o total descrédito lançado sobre as instituições políticas liberais. Certamente, essa é uma das razões pelas quais Manoilesco é tão importante para Azevedo Amaral: ele lhe dá sólidos argumentos analíticos para defender sua proposta, até porque também "o economista romeno" postulava a centralidade das questões econômicas para se entender a crise que se vivia e, ato contínuo, para propor uma saída/solução ancorada no 
estabelecimento de um Estado forte, centralizado, nacionalista e organizado corporativamente.

Dessa forma, uma das contribuições mais decisivas de Manoilesco para o pensamento de Azevedo Amaral é a minuciosa apresentação e defesa, também em O século do corporativismo, do que chama de "teoria dos câmbios internacionais". Nesse sentido, vale lembrar que o outro livro desse autor, publicado em português em 1931, tinha essa tese como central e já vinha circulando nos meios empresarias e políticos do país. Quer dizer, o terreno estava preparado e o espaço de seis anos entre as duas publicações permitia que o autor dele se beneficiasse. De toda forma, esse fato reforça a importância e a influência que essa nova "teoria" de economia política, que vinha sendo elaborada por Manoilesco desde os anos 1920, pode ter tido no Brasil, e não apenas para o pensamento de Azevedo Amaral, como o interesse de Roberto Simonsen deixa muito claro.

Segundo tal teoria, após a Primeira Grande Guerra, o mundo passara por uma profunda transformação na estrutura de sua economia. Se, desde o século XIX, vivera-se uma era de "centralização industrial", com os países industrializados se beneficiando daqueles que eram exportadores de produtos agrários, tal modelo ruíra no pós-guerra, tornando-se impossível a continuidade de sua dominância. Uma tendência à “descentralização industrial”, iniciada ainda durante a guerra e articulada, em alguns casos, a campanhas de "libertação nacional", como ocorreu na Índia de Ghandi, ganhou curso mundialmente. Assim, a economia e também a política mundial entraram em uma nova etapa, uma vez que a "experiência histórica" demonstrara/ensinara como, invariavelmente, os países industriais eram ricos e os "países agrícolas" eram pobres, vivendo em uma "situação de dependência" e de "pobreza", em relação à qual só possuíam um caminho para sua emancipação: o caminho da industrialização. Segundo a "teoria dos câmbios internacionais" de Manoilesco, portanto, dois movimentos tornaram-se claros. O primeiro evidenciava como a situação socioeconômica e política de um país, especialmente os não-industriais, estava submetida a injunções do comércio internacional que extrapolavam as dimensões internas de sua soberania e, em grande parte, os condenavam ao "atraso" no cenário mundial. A segunda mostrava como os abalos provocados pela Primeira Guerra Mundial tornaram possível e mesmo iminente uma era de "descentralização industrial": uma nova etapa histórica no desenvolvimento econômico internacional.

Era aproveitando esse novo contexto, aprofundado pela crise de 1929, que os países, com destaque os agroexportadores, deviam atuar para se afirmar no novo cenário mundial. Essa ação, fundamentalmente, significava promover políticas visando à sua industrialização, o que produziria, como desdobramento "natural", o enriquecimento de sua população e o fim de uma posição de "dependência" no sistema mundial de trocas comerciais. Tal conquista teria 
diretrizes específicas em cada país, uma vez que suas características históricas precisavam ser conhecidas e trabalhadas com acerto, para que o traçado de políticas modernizadoras fosse, de fato, eficiente. Se não havia um receituário padrão, devendo-se respeitar o "caráter nacional" de cada país, havia uma certeza comum: a industrialização/modernização só seria conseguida por meio de um processo de reorganização dos Estados nacionais e de suas sociedades, donde a junção e a decisiva importância dos arranjos corporativistas, não desenvolvidos no livro anterior de Manoilesco. Assim, se nas reflexões traduzidas para o português em 1931 o diagnóstico sobre a situação de "dependência" estava feito, e a saída industrialista encontrada, é só no livro que chega em 1938 que a arquitetura política que permite implementar tal proposta é desenhada: um Estado nacionalista e intervencionista, fundado em diretrizes corporativistas de organização da sociedade.

Por isso, o século XX era o século da industrialização e dos nacionalismos, já que os Estados precisavam se comportar como "verdadeiras autarquias", defendendo seus "interesses gerais", o que não se conseguiria dentro das fórmulas, já comprometidas e viciadas do modelo político liberal representativo. A crítica à teoria de trocas em perfeita competitividade, dominante até então, por incorporar as imperfeições e distorções do mercado, acarretava a necessidade de mudanças nas formas políticas de organização dos Estados nacionais, especialmente traduzidas no aumento de seu poder de governabilidade, vale dizer, de sua capacidade de intervenção em várias dimensões - como as econômicas e sociais - de organização das sociedades. Por isso, o século XX também era o século do corporativismo, pois eram as corporações - reinventadas, mas existentes desde a Idade Média - o novo e estratégico modelo de organização que fundaria essa nova arquitetura de Estados e de sociedades no pós-guerra.

O corporativismo era, nesses termos, apresentado por Manoilesco e lido por Azevedo Amaral, não apenas como uma possibilidade de reforma política da representação liberal; ele era um "verdadeiro" modelo de organização nacional, abarcando instituições/organizações públicas, mas igualmente instâncias privadas, fossem elas de natureza profissional ou não. As corporações se tornavam, nessa teoria, uma espécie de ponto nodal para o desencadeamento de toda uma proposta de reorganização nacional, denominada como autárquica, que é igualmente nacionalizadora e industrializante. Um Estado e uma sociedade corporativos permitiriam a um país agrário-exportador, como o Brasil, a tão almejada modernização/industrialização, entendida como enriquecimento para o povo do país, inclusive para seus trabalhadores, pois eles teriam o valor de sua mercadoria - o trabalho - aumentado. O momento internacional era propício. A "sorte" sorria àqueles que tivessem a "virtude" de promover as mudanças necessárias no tempo certo. Azevedo Amaral escreveria, na biogra- 
fia de Vargas, já em 1941, que ele era o primeiro estadista do Brasil, justamente porque reuniu essas duas condições: teve sorte e tinha virtude.

Como Bolívar Lamounier apontou em seu prefácio à segunda edição de O Estado autoritário e a realidade nacional, Azevedo Amaral chegou ao corporativismo pela industrialização ou, como quero destacar, pela nova "teoria das trocas internacionais". Nesse sentido, é interessante lembrar que vários pensadores brasileiros, entre os quais se destacam Manoel Bomfim e Alberto Torres, ${ }^{8}$ de há muito haviam alertado, embora de forma distinta, mas não menos contundente, sobre a situação de "atraso" do país ante o mercado internacional, apontando a fragilidade de nossa economia agrária e monocultora, aliada a nossos governos "imprevidentes" e "incompetentes", quase sempre endividados e renegociando empréstimos em situações desfavoráveis. Para Bomfim, também amante de metáforas organicistas, a situação dos países ricos, muitos deles colonizadores, era a de autêntico parasitismo, pois viviam sugando os países "atrasados", deixando-os empobrecer, sem qualquer pudor. Já para Alberto Torres, referência intelectual nos anos 1930/40, chegando a ser consagrado como o maior inspirador dos "reformadores" dessas décadas, "não havia bons colonizadores", motivo pelo qual os países que tinham sido colônias precisavam lutar arduamente para se afirmar internacionalmente, através de ações políticas de "organização nacional". Para Torres, cujas obras datam do início do século XX, a maior preocupação era com a modernização do campo, dominado pela monocultura e pela grande propriedade, e não com a industrialização, como ocorrerá com Azevedo Amaral, na esteira das experiências do pós-1929.

Mas de qualquer forma, o que se deseja assinalar é que as "descobertas" de Manoilesco encontraram terreno fértil, adubado por outros pensadores e regado pelo descrédito no liberalismo político, muito compartilhado pelos intelectuais brasileiros a partir dos anos 1920, fossem eles claramente favoráveis ao seu total abandono ou "apenas" (o que não era pouco, aliás) desejassem a reforma de diversos de seus procedimentos. De toda forma, havia entre a maioria da intelectualidade brasileira uma convergência quanto ao fato de o Estado precisar ser transformado, saneado e reforçado, para se tornar o principal agente diretor de um processo de modernização do país. Para quase todos eles, ante um território imenso e desocupado, uma sociedade composta em grande parte por analfabetos, e assolada por doenças epidêmicas, uma administração frágil e sem meios de comunicação eficazes, só um Estado forte e com maior capacidade de intervenção poderia ter alguma chance de vitória ante os imensos problemas a vencer.

Dessa forma, talvez o que livro de Manoilesco tenha trazido de mais precioso para Azevedo Amaral e outros leitores, foi o sentimento de urgência, diante do convincente e cuidadoso diagnóstico sobre o momento que se vivia internacionalmente. Um momento de grave crise e, na interpretação que se fazia, por isso mesmo um momento de oportunidades para as nações "atrasa- 
das", ex-colônias, não industrializadas. Era tal momento que não devia ser perdido, em especial no Brasil que, em 1930, vivera uma "revolução", divisando uma abertura de horizontes para a realização de mudanças de há muito desejadas. Uma situação que fora reforçada pelo golpe do Estado Novo, que instaurara um Executivo forte e dissolvera o Legislativo, o que criava novas condições para uma reorganização nacional em bases corporativistas. Assim, talvez o louvor ao Estado Novo, em início de 1938, tivesse o objetivo de alertar as elites políticas para a necessidade de se aproveitar aqueles anos para transformar o Brasil: para industrializá-lo e modernizá-lo, o que era dizer a mesma coisa para Azevedo Amaral.

\section{O ESTADO AUTORITÁRIO E O CORPORATIVISMO DE AZEVEDO AMARAL}

O Estado autoritário e a realidade nacional foi, de fato, um livro influente nos poucos anos em que circulou, já que após 1945, com o fim do Estado Novo, seu autor e sua obra tenham caído no "esquecimento", sendo taxados de fascistas e sem qualquer valor intelectual. Só nos anos 1970/80, quando o Brasil voltou a viver sob um regime autoritário, o interesse acadêmico para com esses pensadores se adensou e resultou em diversos estudos que constataram o quanto tais pensadores foram argutos em suas análises, e o quanto suas ideias deixaram marcas na cultura política republicana do pós-30. Contudo, no caso de Azevedo Amaral, pode-se aventar que sua maior contribuição não tenha residido na explanação de uma arquitetura corporativista para uma nova "organização nacional". Outros autores, em especial Oliveira Vianna, foram mais minuciosos em seus textos e mais atuantes em sua ação política, o que certamente contribuiu para uma posição de mais destaque quando se trabalha com o tema do corporativismo e também do sindicalismo. ${ }^{9}$

Examinando o livro com atenção, verifica-se que não há tanto espaço dedicado às reflexões sobre o corporativismo. Mesmo considerando que o procedimento de citações não era muito praticado pelos autores nos anos 1930/40, sobretudo aqueles que escreviam ensaios, como é o caso, vale notar que 0 século do corporativismo, traduzido quase ao mesmo tempo da escrita do volume, tenha sido mencionado apenas uma vez. ${ }^{10}$ Tal citação, inclusive, é feita quase ao fim do livro, justamente para reforçar "os métodos de organização da produção e do comércio" através das corporações, em função do que Manoilesco chamava de "imperativos da solidariedade nacional". Isto é, da necessidade de as "forças nacionais" organizadas serem "coordenadas" pelo Estado, para que o "bem coletivo" ou o "interesse nacional" fosse alcançado no novo cenário de intercâmbios internacionais. Dessa forma, são evidentes os ecos da teoria das trocas internacionais nessa única menção explícita, deixando-se claro que o corporativismo era um "método" de organização das forças/interesses sociais. Estas deviam existir e se manifestar, mas precisavam ser coordenadas pelo 
Estado para que a "solidariedade nacional" fosse atingida e, com ela, a modernização do país.

Há, naturalmente, a citação de outros autores e livros, sendo três deles do próprio Azevedo Amaral, ${ }^{11}$ e mais três de autores nacionais: Casa grande \& senzala, de Gilberto Freyre (1933); Mauá, de Alberto de Faria (1927) e Aspectos da política econômica nacional, de Roberto Simonsen (1935). São um pouco mais numerosas as referências a autores internacionais (nove livros), geralmente trabalhos sobre economia, ${ }^{12}$ havendo um sobre o corporativismo, ${ }^{13}$ tema de bom trânsito no mercado de livros brasileiro nos anos 1930.

Não é o caso, nos limites deste artigo, de comentar as leituras de Azevedo Amaral, pois o ponto que se quer destacar como mais polêmico e interessante é exatamente a defesa e a demarcação do que chama de Estado autoritário. Uma reflexão bastante original, pois nenhum dos demais pensadores seus contemporâneos se dedicou com tanto cuidado ao traçado de uma tipologia que distinguisse e defendesse as virtudes do autoritarismo, em relação ao liberalismo e ao totalitarismo, como ele. Essa proposta é valiosa, porque é exatamente na defesa de um Estado autoritário que ele caracteriza a importância de haver corporações "de fato", e não simplesmente órgãos completamente submetidos ao Estado. Esta é a mesma crítica, presente em seu Prefácio de $O$ século do corporativismo, ao exemplo italiano.

Como já assinalado, realizar tal distinção não era fácil e, obviamente, era algo bem conveniente por razões políticas e intelectuais. Não "aderir" a qualquer dos blocos, naquele momento de pré-Segunda Guerra Mundial, era interessante, embora também seja fundamental lembrar que, em 1938, a Alemanha de Hitler não era considerada pela União Soviética uma inimiga, o que só ocorrerá posteriormente. ${ }^{14}$ De toda forma, se os Estados totalitários podiam ser admirados pelo que traziam de modernização às suas nações, eram também criticados em função da total supressão de áreas de liberdade em duas situações entendidas como inegociáveis para Azevedo Amaral: a liberdade de iniciativa no campo da economia, o que remetia aos postulados do liberalismo econômico; e a liberdade de cunho cultural, como a religiosa e artística, desde que, evidentemente, não se ferisse a "solidariedade nacional", que devia ser garantida pelo Estado.

Uma boa parte do livro de Azevedo Amaral é dedicada a expor e a insistir na importância da manutenção dessas margens de liberdade para que um real progresso nacional fosse alcançado, o que remete diretamente à sua tese do autoritarismo e sua não assimilação ao fascismo. Quanto ao liberalismo, estava bem claro que a rejeição radical era a seus procedimentos políticos, até porque o fundamento teórico-filosófico da doutrina liberal era um engano: não se podia considerar os homens iguais e tratá-los como tais numa sociedade de massas como a moderna sociedade do século XX. A presença do Estado em esferas impensadas no modelo político liberal era uma necessidade indis- 
cutível, como evidenciava a experiência americana do New Deal de Roosevelt, muito apreciada e comentada por Azevedo Amaral e, aliás, não apenas por ele, como ilustra o exemplo de Oliveira Vianna.

O que os EUA mostravam ao mundo é que eram as novas configurações do capitalismo - não mais valorando o individualismo de forma ilimitada, nem acreditando na positividade absoluta das "leis do mercado livre" -, que traziam desenvolvimento às nações, fundavam um novo modelo ou tipo de capitalismo: o capitalismo corporativo ou neocapitalismo (Amaral, 1938: 125). O autor, portanto, queria deixar bem claro que não aprovava qualquer proposição de tipo socialista/comunista, mantendo-se o Estado autoritário no campo do capitalismo mais avançado, a exemplo dos EUA de Roosevelt. Eliminando-se os excessos de "fatalismo das supostas leis econômicas" do mercado, e os excessos de intervencionismo totalitário que destruíam a iniciativa privada, a liberdade de culto e de criação dos indivíduos, alcançava-se um Estado suficientemente forte para realizar a "sistematização racional" dos interesses sociais em razão do "bem coletivo".

Tal sistematização se faria por meio de uma reorganização corporativa da sociedade, especialmente no que se referia às organizações profissionais, que eram, por excelência, os sindicatos de "empregados e empregadores". Era deles que partia, predominantemente, a expressão da vontade nacional, razão pela qual não podiam se tornar uma mera correia de transmissão de orientações estatais, devendo haver uma mútua alimentação entre Estado e corporações profissionais. Era dessa relação, que envolvia coordenação do Estado, mas também iniciativa privada, que nascia a "democracia autoritária" do Estado Novo brasileiro. Para Amaral, algo que o artigo 61 da Constituição de 1937 cuidava de regulamentar, ao atribuir ao Conselho Nacional de Economia o encargo de promover a organização corporativa da economia no país. Uma instituição que nunca foi implementada, algo que, evidentemente, Azevedo Amaral não sabia em 1938.

Sem dúvida, tratava-se de um ajuste delicado, buscando-se equilibrar o que se considerava produtivo de dois modelos que se antagonizavam, reforçando, como Amaral mesmo criticou em Manoilesco, a crença nas virtudes daqueles que dariam vida a tal proposta. No caso do economista romeno, em Mussolini, e no de Azevedo Amaral, no "gênio" de um Vargas estadista. De toda forma, essa crença não era algo cosmético ou secundário na proposta dos dois autores. Ou seja, se ambos davam enorme peso aos "determinismos" de uma nova era de "descentralização industrial" e de transformações no mercado de trocas internacionais, entendiam que a vontade humana não podia faltar, direcionando as políticas que deviam e podiam ser desenvolvidas. O Estado intervencionista tinha um "sentido voluntarista", tanto melhor canalizado, quanto maiores as virtudes do estadista em sua chefia. 
Azevedo Amaral morreu em novembro de 1942, quando o Brasil já entrara na Segunda Guerra Mundial, alinhando-se com os EUA. Na mesma ocasião em que o ministro do Trabalho, Indústria e Comércio, Alexandre Marcondes Filho, estava desencadeando uma política que resultaria na conformação de uma ideologia trabalhista no Brasil. Os ventos estavam mudando de direção, e os integrantes da cúpula política do Estado Novo começavam a preparar um processo de transição - que desejavam o menos custoso possível para suas posições de poder - de saída do autoritarismo. Diferentemente do ano de 1938, já não era tão adequado tecer elogios a um Estado autoritário, embora a proposta corporativista estivesse sendo utilizada como uma das pedras de toque de uma política trabalhista que precisaria incorporar, de alguma forma e em futuro não muito distante, a figura do eleitor. Trabalhadores organizados em sindicatos podiam se tornar eleitores valiosos, desde que mobilizados por uma retórica que evidenciasse o valor da nova legislação trabalhista, entre outras políticas sociais de Vargas.

Por conseguinte, foi nesse momento de mudanças que Azevedo Amaral faleceu, e os maiores jornais do Distrito Federal e do país abriram espaço para a publicação de necrológios sobre esse "ilustre jornalista". Contudo, são eles mesmos que registram que a Associação Brasileira de Imprensa (ABI) não enviou representante ao velório, o que é um indicador para se pensar o quanto a $A B I$ não desejava se aproximar de um "publicista" tão identificado com a ditadura do Estado Novo. Para o historiador, uma oportunidade de aproximação das visões dos contemporâneos sobre a atuação do morto, com destaque para suas maiores contribuições, já que são os elogios ao personagem morto que compõem a principal razão dos necrológios. Examinando alguns deles, o que chama a atenção não é o fato de Azevedo Amaral ser saudado como um grande jornalista, diretor de periódicos, além de redator de artigos e colunas em numerosas folhas, durante décadas. O que impressiona é não ter sido destacado como autor de livros importantes, que marcaram os debates dos anos 1930. Apesar disso, era reconhecido como um pensador que, "por sua qualidade de espírito fazia jus ao respeito de todos, até daqueles que discordavam de suas ideias" (Arlindo Vieira, 1942). ${ }^{15}$ Um comentário sutil, mas que permite especulações sobre o incômodo que as ideias de Amaral traziam, ao menos nos meios ilustrados de uma imprensa, majoritariamente, de oposição a Vargas.

De toda forma, as razões para tais cuidados podem ser apenas imaginadas, estando preferencialmente explicadas pelo contexto político do ano de 1942, ao que se somava uma atuação como jornalista muito mais longa de que como ensaísta. Aliás, os necrológios registram que só nos anos 1930 Amaral passou a escrever livros porque, atingido pelo mal da cegueira, teve que ir abandonando a rotina das redações e dos regulares artigos de jornal. O que se retém das notícias é que seu enterro foi melancólico, em tarde de domingo cinzenta e com pouca gente. Um clima que se estenderia cada vez mais à me- 
mória de seus trabalhos, a partir do fim do Estado Novo. Nos anos 1950, ele praticamente deixou de ser lido e citado; uma tendência que só se reverteria nas décadas finais do século XX, quando os temas do autoritarismo e do corporativismo o trouxeram de volta para integrar uma biblioteca do pensamento político republicano.

Recebido para publicação em agosto de 2012.

Angela de Castro Gomes é professora e pesquisadora sênior do Centro de Pesquisa e Documentação em História Contemporânea (CPDOC), da Fundação Getulio Vargas (FGV), professora titular de

História do Brasil da Universidade Federal Fluminense (UFF) e pesquisadora do Conselho Nacional de Desenvolvimento Científico e Tecnológico (CNPq). Entre suas publicações mais recentes estão, entre outros, A República, a História e o IHGB (2009) e "Estado Novo: ambiguidades e heranças do autoritarismo no Brasil” (2010). 


\section{NOTAS}

1 Estou trabalhando com a primeira edição do livro em português. Ele tem 228 páginas e seu prefácio, peça fundamental de análise, vai da página V à VII. Todas as citações que se seguem são destas páginas. Este texto foi apresentado no Internacional Congress of Americanists, Viena, julho de 2012, no Simpósio Corporatist States and Ideas in Europe and Latin America.

2 Recentemente esse livro ganhou uma nova edição no Brasil. Ver Manoilesco (2011).

3 Essa noção de imperfeição do mercado de trocas internacionais só seria incorporada pela economia no fim da década de 1950, reconhecendo-se que, nas condições em que Manoilesco escreveu, o protecionismo, mesmo não sendo mais entendido, nesta década, como a melhor resposta, era a melhor resposta possível em seu contexto. Por isso, foi considerado como inegavelmente superior ao livre mercado para os países "agrícolas", como o Brasil.

4 Usaremos aqui a $2^{a}$ edição (Brasília: Ed. UnB, 1981) publicada na Coleção Pensamento Político Republicano.

5 Apenas para se ter uma ideia da importância dessa editora, entre seus autores estavam: Manuel Bandeira, Carlos Drummond de Andrade, José Lins do Rêgo, Raquel de Queiroz, Gilberto Freyre, José Américo de Almeida, entre outros grandes romancistas, poetas e ensaístas brasileiros.

6 Esta edição integra a Biblioteca do Pensamento Político Republicano, sendo seu volume de número 11. Ver, entre outros, Oliveira (1982), Alcântara (1967), Medeiros (1978) e Piva (2000).

7 São numerosos os trabalhos sobre esta questão, não valendo aqui citá-los para não sobrecarregar o texto.

8 Sobre Manoel Bomfim, ver Botelho (2009) e Gontijo (2003). Sobre Alberto Torres, ver o trabalho clássico de Lima Sobrinho (1968), entre muitos outros.

9 Tenho vários estudos sobre Oliveira Vianna e o considero o autor mais influente no que diz respeito à montagem de um modelo sindical corporativista no Brasil. Entre eles, ver Gomes (2008 e 2009). 
10 Ver Amaral (1938: 152 da 2. ed., com a qual estou trabalhando). O autor cita o livro em francês e em português, assinalando que a tradução era de sua autoria.

11 Os livros são: A aventura política do Brasil (1935), Ensaios brasileiros (1930) e O Brasil na crise atual (1934), já mencionados.

12 Ele cita livros em inglês e francês, como, por exemplo, A New Deal e The economy of abundance, de Stuart Chase, ambos de 1934, e Gramaire de la politique, de Harald Laski, s/d.

13 O livro é La corporation dans le monde, de G. de Michelis ( $\mathrm{Pa}$ ris, 1935), tradução de La Corporazione nel mondo (Milão, 1934).

14 No Brasil, um jornal como o Meio Dia, publicado por editora do mesmo nome entre 1939 e 1942, de propriedade de Joaquim Inojosa, um ex-modernista simpatizante de Hitler, contava com colaboradores como Jorge Amado, encarregado da seção "Letras - Artes - Ciências", e Oswald de Andrade, que escrevia as colunas "Banho de Sol" e "De Literatura", entre outros intelectuais sabidamente ligados ao Partido Comunista Brasileiro. Sobre Inojosa, ver Barros (2012).

15 Trabalhamos também com os necrológios do Jornal do Brasil ("Azevedo Amaral: o falecimento ontem desse ilustre jornalista", 8 nov. 1942); de A Manhã ("Pequeno enterro de um grande jornalista", 11 nov. 1942) e O Jornal ("Azevedo Amaral", 10 nov. 1942).

\section{REFERÊNCIAS BIBLIOGRÁFICAS}

Alcântara, Aspásia B. A teoria política de Azevedo Amaral. DADOS, 1967, 2-3, p. 194-224.

Amaral, Azevedo. Getúlio Vargas - estadista. Rio de Janeiro: Pongetti, 1941.

. O Estado autoritário e a realidade nacional. Rio de Janeiro:

José Olympio Editora, 1938.

A aventura política do Brasil. Rio de Janeiro: Livraria José Olympio Editora, 1935.

O Brasil na crise atual. São Paulo: Companhia Editora Nacional, 1934. 
Ensaios brasileiros. Rio de Janeiro: O. Menna Barreto, 1930.

Arlindo Vieira, P. O jornalista Azevedo Amaral. A Manhã, 5 dez. 1942.

Barros, Natália C. Silva. Arquivos da vida, arquivos da história: as experiências intelectuais de Joaquim Inojosa e os usos da memória do modernismo. Tese de Doutorado. Universidade Federal de Pernambuco, 2012.

Botelho, André. Manoel Bomfim: um percurso de cidadania no Brasil. In: Botelho, André \& Schwarcz, Lilia M. (orgs.). Um enigma chamado Brasil. São Paulo: Companhia das Letras, 2009, p. 118-131.

Cândido, Antônio. A Revolução de 30 e a cultura. In:

A educação pela noite e outros ensaios. São Paulo: Ática, 1989, p. 181-198.

Gomes, Angela de Castro. Autoritarismo e corporativismo no Brasil: intelectuais e construção do mito Vargas. In: Pinto, Antônio Costa \& Martinho, Francisco C. Palomanes (orgs.). O corporativismo em português: Estado, política e sociedade no salazarismo e no varguismo. Rio de Janeiro: Civilização Brasileira, 2007.

- Oliveira Vianna: um statemaker na alameda São Boa Ventura. In: Botelho, André \& Schwarcz, Lilia M. (orgs.). Um enigma chamado Brasil. São Paulo: Companhia das Letras, 2009, p. 144-159.

A construção de mitos e os usos do passado nacional: Vargas e Perón. História, 1997, 16, p. 109-130.

Gontijo, Rebeca. Manoel Bomfim, pensador da história na Primeira República. Revista Brasileira de História, 2003, 23/45, p. 129-154.

Lamounier, Bolívar. Introdução. In: Amaral, Azevedo. O Estado autoritário e a realidade nacional. 2. ed. Brasília: Ed. da UnB, 1981.

Lima Sobrinho, Barbosa. Presença de Alberto Torres: sua vida e pensamento. Rio de Janeiro: Civilização Brasileira, 1968.

Manoilesco, Michael. Teoria do protecionismo e da permuta internacional. Rio de Janeiro: Capax Dei, 2011.

Medeiros, Jarbas. Ideologia autoritária no Brasil: 1930/45. Rio de Janeiro: Ed. FGV, 1978. 
Oliveira, Lúcia L. Autoridade e política: o pensamento de Azevedo Amaral. In: Oliveira, Lúcia L., Velloso, Mônica P. \& Gomes, Angela de C. Estado Novo: ideologia e poder. Rio de Janeiro: Zahar, 1982, p. 48-70.

Piva, Luiz Guilherme. Ladrilhadores e semeadores: a modernização brasileira no pensamento político de Oliveira Viana, Azevedo Amaral e Nestor Duarte (1930-1940). São Paulo: Ed. 34, 2000.

Pontes, Heloísa. Retratos do Brasil: um estudo dos editores, das editoras e das coleções brasilianas nas décadas de 1930, 40 e 50. BIB, 1988, 26, p. 58-67.

Villaça, Antonio Carlos. José Olympio: o descobridor de escritores. Rio de Janeiro: Thex, 2001. 


\section{Palavras-chave: Resumo:}

Azevedo Amaral; Intelectuais; Autoritarismo; Corporativismo; Estado Novo.

\section{Keywords:}

Azevedo Amaral; Intelectuals; Authoritarianism; Corporativism; Estado Novo.
Este artigo tem como objetivo de fundo acompanhar o processo de circulação e apropriação de ideias sobre o modelo corporativista de organização do Estado e da sociedade, no Brasil dos anos 1930/40. Para tanto, escolheu trabalhar com a atuação de um dos mais importantes intelectuais desse período: Azevedo Amaral. Este intelectual se dedicou a traduzir para o português, o livro de Michael Manoilesco, O século do corporativismo, do qual escreve o prefácio, em 1938. Nos anos 1930, produz também vários livros, entre os quais, o Estado autoritário e a realidade nacional, igualmente datado de 1938 e publicado pela editora José Olympio, no qual faz uma aposta imediata no modelo autoritário e corporativista de Estado para o Brasil.

\section{Abstract:}

This paper aims to follow the process of circulation and appropriation of ideas about the corporatist model of organization of state and society in Brazil in the years 1930/40. To do so, we will use the intellectual production of Azevedo Amaral, who - besides translating for Portuguese the book The century of corporatism by Michael Manoilesco - wrote many others important works, like O Estado autoritário e a realidade nacional, in which he theorized about the application of these ideas in Brazil. 